Fabian Schmid, Joscha Winzer, André Pasemann, Frank Behrendt

\title{
An open-source modeling tool for multi- objective optimization of renewable nano/ micro-off-grid power supply system: Influence of temporal resolution, simulation period, and location
}

Journal article | Accepted manuscript (Postprint)

This version is available at https://doi.org/10.14279/depositonce-11282

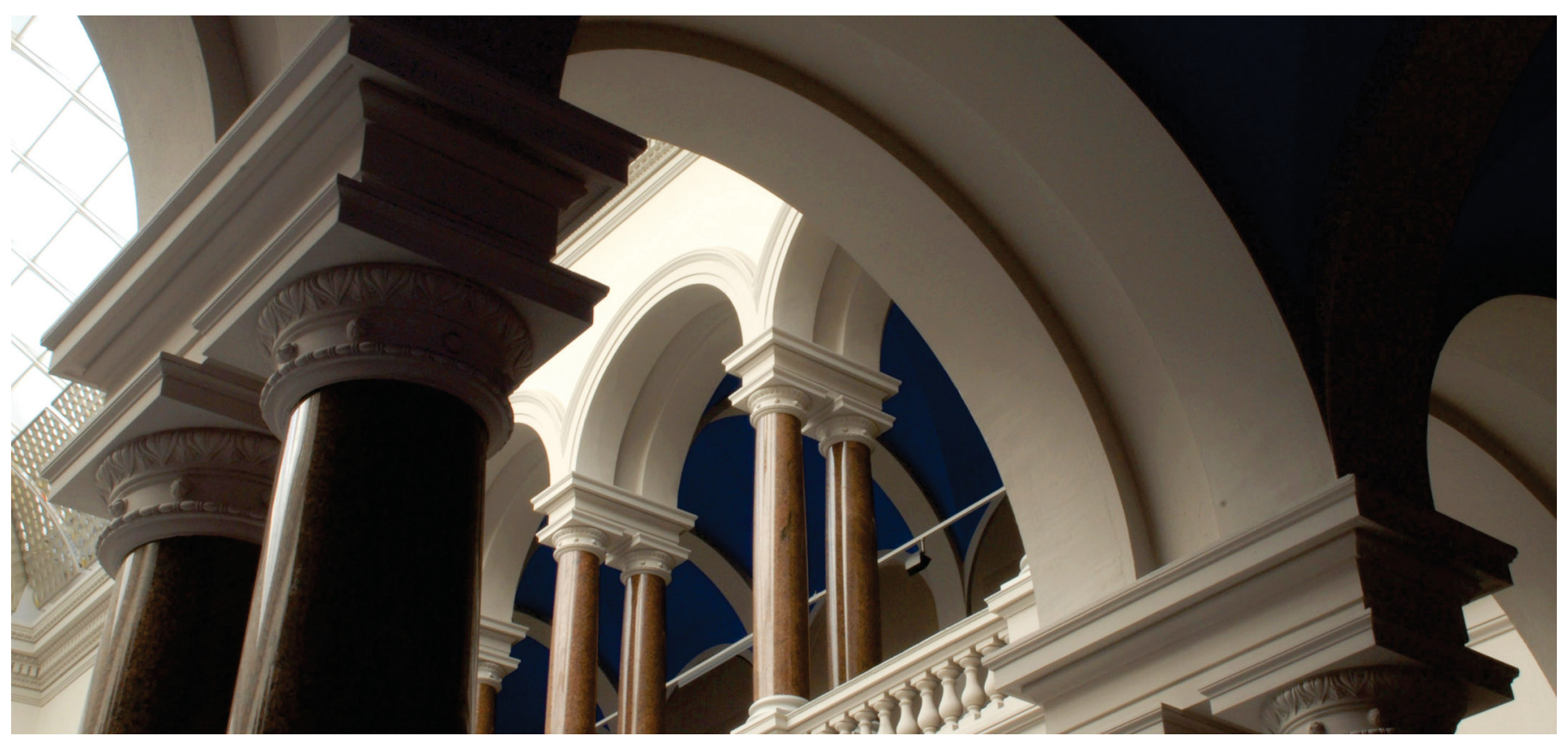

Schmid, F., Winzer, J., Pasemann, A., \& Behrendt, F. (2021). An open-source modeling tool for multiobjective optimization of renewable nano/micro-off-grid power supply system: Influence of temporal resolution, simulation period, and location. Energy, 219, 119545.

https://doi.org/10.1016/j.energy.2020.119545 


\title{
An open-source modeling tool for multi-objective optimization of renewable nano/micro-off-grid power supply system:
}

\section{Influence of temporal resolution, simulation period, and location}

\author{
Fabian Schmid a , email: fabian.schmid@tu-berlin.de \\ Joscha Winzer ${ }^{\text {b }}$, email: joscha.winzer@betteries.com \\ André Pasemann c, email: andre.pasemann@vsb.energy
}

Prof. Dr. Frank Behrendt a , email: frank.behrendt@tu-berlin.de

a) Technische Universität Berlin, Institute for Energy Engineering, Chair for Energy Process Engineering and Conversion Technologies for Renewable Energies, Strasse des 17. Juni 135, 10623 Berlin, Germany

b) betteries AMPS GmbH, Goerzallee 299, 14167 Berlin

c) VSB Holding GmbH, Schweizer Strasse 3a, 01069 Dresden

\section{KEYWORDS}

- Open-source energy system modeling tool

- Renewable nano/micro-off-grid power supply system

- Multi-objective optimization

- High temporal resolution

- Influencing factor analysis

\section{HIGHLIGHTS}

- Multi-objective optimization of photovoltaic-battery off-grid system

- Detailed datasheet-based modeling approach

- New energy-based Depth of Discharge model which uses voltage correlation

- System location shows high influence on levelized costs of energy

- Low temporal resolution leads to underestimation of system costs and load outages

Accepted manuscript of: Schmid, F., Winzer, J., Pasemann, A., \& Behrendt, F. (2021). An open-source modeling tool for multi-objective optimization of renewable nano/micro-off-grid power supply system: Influence of temporal resolution, simulation period, and location. Energy, 219, 119545. https://doi.org/10.1016/j.energy.2020.119545

(C) 2020. This manuscript version is made available under the CC-BY-NC-ND 4.0 license http://creativecommons.org/licenses/by-nc-nd/4.0/ 


\begin{abstract}
A fundamental understanding of the sizing process is a key element for sizing affordable, reliable, and sustainable nano/micro-off-grid systems. Nevertheless, the openness and transparency of modeling approaches are still low and open-source tools are scarce in this field. In this study, an open-source modeling tool for the optimization of renewable nano/micro-off-grid power supply systems is developed. System component models based on datasheets consider dynamic and time-dependent influencing factors. The modeling tool uses a multi-objective optimization based on the Non-Sorting-Genetic-Algorithm-II aiming at minimizing costs and load outage. For a better understanding of the sizing process, the influence of temporal resolution, simulation period, and location on the Pareto-optimal fronts is analyzed. The system location and by that irradiance, ambient temperature, and wind speed shows to be the strongest influence factor, which leads up to 2-5 times higher costs for achieving the same security of energy supply. While a higher temporal resolution increases the costs and load outages due to a more realistic illustration of energy production and demand, a shorter simulation period shows an increase in the system costs but a reduction of load outages because of the non-observance of component replacement, its cost reduction, and degradation.
\end{abstract}




\section{INTRODUCTION}

Nowadays, approximately 789 million people still lack access to electrical energy. The majority of these people live in rural areas apart from electricity supply grids [1]. They rely on the usage of non-electric light sources as well as car batteries or small petrol generators as a mobile energy supply. These energy sources are both high in energy costs and cause massive damage to health and the environment. However, an affordable, reliable, and sustainable energy supply is a key factor to prosperity and to ensuring the people's economic participation by increasing the local added value [2]. For the reasons cited above, off-grid power supply systems in combination with renewable energy conversion technologies provide a suitable alternative for these people in question. According to the Renewable 2019 Global Status Report, a total of 150 million people across Africa and Asia gain access to electricity through solar-based off-grid systems. In 2018 the sales volume increased by $45 \%$ compared to the previous year and lead to a total installed capacity of $58.8 \mathrm{MW}$ [3].

It is widely accepted that the term "off-grid" defines systems that operate independently from the main grid and include a local power generation. A number of standards developed by the International Electrotechnical Commission (IEC) regarding microgrids for decentralized rural electrification purposes distinguish between individual electrification systems and collective electrification systems [4]. The International Renewable Energy Agency (IRENA) follows these standards by defining stand-alone systems and mini-grid systems, which are further classified into Pico- (0-1 kW), Nano- (0-5 kW), and Micro-off-grid systems (5-100 kW) according to their size, as well as their system capability and complexity [5].

Due to an uncertain load and fluctuating energy sources, sizing off-grid systems with integrated renewable energy sources is a complex task. Therefore, research in the field of off-grid power supply system modeling and optimization has been done extensively. Many studies were conducted regarding hybrid systems with renewable and fossil energy sources. Cai et al. present a novel framework for optimal sizing and location identification of a photovoltaic-battery-diesel system and state the need for appropriate sizing methods [6]. Different optimization methods are compared but the mathematical system model is comparatively simple. Rodríguez-Gallegos et al. propose a multi-objective optimization method for the integration of photovoltaic and battery components in diesel-driven off-grid systems using a genetic algorithm [7]. This is pursued in [8] and a diesel replacement strategy for off-grid systems with the progressive integration of photovoltaic and batteries is described. Both studies are based on a simple battery model approach. Jaszczu et al. conduct a genetic multi-objective optimization of a micro-grid hybrid power system focusing on the applied objective functions but lacking a detailed description of the mathematical system model [9]. Both before mentioned studies use state-of-the-art optimization methods based on evolutionary algorithms. Zitzler et al. conduct a comparative study of multiobjective evolutionary algorithms and map the algorithm performance according to the distribution of found solutions, the extent of the obtained Pareto-front and the distance of the found optimal set to the real Paretofront [10].

The battery is one of the most significant components in off-grid power supply systems and affects in case of an inappropriate design, system reliability and costs. Integrating appropriate battery models reflecting real-life behavior is therefore crucial for off-grid system sizing [11]. Bordin et al. developed a methodology to analyze the optimal cost-effective battery operation of photovoltaic diesel off-grid systems. It includes the battery degradation process inside a linear programming optimization model [12]. Other studies highlight the importance of battery degradation integration into optimal sizing methods of renewable off-grid power supply systems (e.g. in [13], [14]).

Regarding photovoltaic-battery pico/nano/micro-off-grid power supply systems, Khatib et al. provide an overview of studies and highlight that accurate modeling of all subsystems is required for an appropriate system sizing. Common sizing techniques are classified into intuitive, numerical, and analytical approaches. Intuitive sizing methods are most commonly applied as they are very simple and reduce time and cost of engineering and software licenses [15]. This is especially the case in the practical field and results in system configurations that are not adapted to the specific use case. Poorly sized systems have a higher risk of failure and increase the overall system costs. Ringkjøb et al. present a review of recent modeling tools for electricity systems with a large share of renewables [16]. Only a small part of these tools is open-source, with insight into the model structure, the possibility of code adaption, and free of charge. The authors further state a need for openness and transparency in modeling studies. Among the reviewed simulation tools, no open-source model specifically developed for renewable nano/micro-off-grid power supply system is listed, which represents the lack of such tools. 
Khatib et al. state as well that new sizing methods and a better understanding of influencing factors are required to achieve accurate results with less computing time [15]. Studies which aim for a better understanding of the sizing process, focus mainly on the temporal resolution of load profiles and energy sources. Tjaden et al. and Wrigh et al. state that lower temporal resolution of load curves results in too optimistic matches of load and power generation [17], [18]. Stenzel et al. evaluate the impact of temporal resolution of supply and demand profiles of a photovoltaic battery grid-tied system and state that the accuracy of the simulation results increase with increasing temporal resolution [19]. Beck et al. analyze a comparable system configuration for Germany but state that for optimal sizing of the photovoltaic and battery capacity a resolution of 60 min is sufficient [20]. Burgio et al. evaluate the impact of data averaging and temporal resolution on grid-tied hybrid photovoltaicbattery systems and state that the temporal resolution has no particular relevance in the optimal sizing of the system to guarantee a $100 \%$ self-generation rate but they analyze only a simulation period of one year [21]. Tang et al. give an overview of the temporal resolution applied in photovoltaic battery optimization studies and state that mainly a relatively low resolution is used. They further identify that for their cost optimization hourly temporal resolution could lead to underestimations [22]. Studies regarding the influence of the simulation period and system location on the sizing process could not be identified.

This paper proposes an open-source modeling tool for the simulation and optimization of photovoltaic-battery nano/micro-off-grid power supply systems. All system component models can be parametrized by open-access or datasheet data. This shall gap the lack of open-source numerical sizing approaches and increase the transparency of developed mathematical system models. The practical application of the developed tool is presented through a multi-objective optimization to identify optimum trade-offs between two conflicting objectives which are the minimal costs (Levelized Costs of Electricity) and the load outages (Loss of Load Probability) of the system. Therewith, the work brings the following major contributions for the numerical sizing process of photovoltaic-battery nano/micro-off-grid power supply systems:

- An innovative battery model with a new energy-based Depth of Discharge (DoD) model to meet the needs for accurate battery representation.

- Contribution towards a better understanding of the sizing process through an influencing factor analysis. Detailed analysis of the sizing process regarding the influence of the temporal resolution and simulation period for the used load profiles and weather data which changes with the system's location.

The system studied, developed mathematical component models, and methods applied are introduced in chapter 2 . In chapter 3 the main findings of the influencing factor analysis are presented and discussed. We finish the paper with conclusions on the numerical sizing process and an outlook of future work.

\section{METHODS}

A system simulation for a multi-objective optimization and sizing procedure needs to describe all energy flows inside the system. Additionally, it is necessary to describe the dynamic behavior inside the chosen temporal resolution and the aging processes which occur during the simulated period. Further requirements for a general model include the following:

- $\quad$ Easy model parametrization based on datasheets, measurements or online-databases

- Interconnection between sub-models must be unambiguous to support a model exchange or extension

- Models must be sufficiently flexible concerning the design variables

- The computational effort must be small due to the high temporal resolution, high number of parameters, and iteration steps which are caused by the optimization procedure

Besides the mentioned requirements, the developed simulation model follows a power flow approach. For the reason of simplicity and simulation computing time, only the component's power flows are considered without modeling individual current and voltage levels. 


\subsection{System description}

In Figure 1 the analyzed nano/micro-off-grid power supply system is schematically depicted. It consists of a photovoltaic (PV) array, a Maximum Power Point Tracker (MPPT), a Lithium-Iron Phosphate (LFP) battery with an

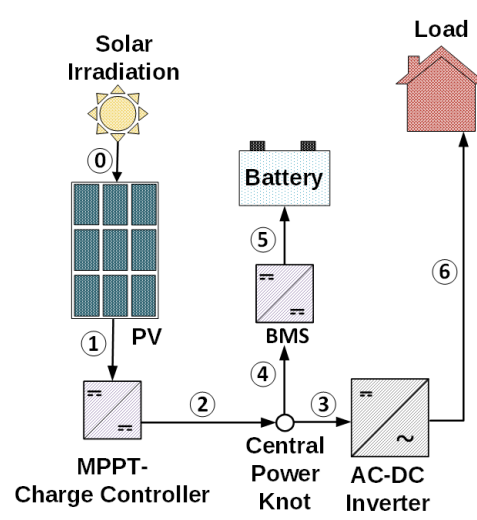
active Battery Management System (BMS), and an AC-DC power inverter. Arrows represent the modeled power flows between the system components. The arrow direction indicates the sign rule in the simulation though not necessarily the direction of energy flow. The direction of power flow 4 and 5 is reversible in the case of battery discharge. The battery charge power is positive and the discharge power is negative, contrary to the ISO12405-1-norm [23].

Further connection and safety components are neglected in the technical model and estimated by a rough rule of thumb values of the literature in the economic model. The energetic losses of operations control and monitoring components are integrated into the charge-controller and inverter models.

Figure 1 System diagram.

\subsection{Mathematical model}

This section provides a detailed description of the developed mathematical models of all technical system components and the used simulation input data.

\subsubsection{Photovoltaic model}

For long-term system simulations, constant efficiency models are most commonly used, although most models in the literature are based on electrical circuit models (ECM) to model the U-I-curve of the photovoltaic module [24]. However, it is not necessary to model the whole U-I-curve since only systems with MPPT are considered. Therefore, it can be assumed that the photovoltaic module runs mostly at its maximum power point if the load side is not restricted otherwise, e.g. by full batteries and insufficient load. Furthermore, the lowest simulation time step of 1 minute is high enough to neglect the energy losses due to the search algorithm of the MPPT and by that the effect of suboptimal voltage and current operation points of the photovoltaic module.

Therefore, the simple photovoltaic model from [25] is applied:

$$
P_{M P P, P V}=\frac{G}{G_{r e f}} \cdot P_{M P P, r e f} \cdot \gamma_{0} \cdot\left(T_{c}-T_{r e f}\right)
$$

The $\mathrm{P}_{\mathrm{MPP} \text {,ref }}$ describes the output power at the maximum power point and Standard Test Conditions (STC) with $\mathrm{T}_{\text {ref }}=298.15 \mathrm{~K}$ and $\mathrm{G}_{\text {ref }}=1000 \mathrm{~W} \cdot \mathrm{m}^{-2}$ and $\gamma_{0}$ the power-dependent temperature coefficient (assumed to be $\left.\gamma_{0}=-0.5 \mathrm{~W} \cdot \mathrm{K}^{-1}\right), \mathrm{T}_{\mathrm{c}}$ the variable cell temperature and $\mathrm{G}$ the effective irradiation respectively. The accuracy of this model which was tested by [25] in a practical one-year study with mono-crystalline panels and MPPT is similar, sometimes even exceeding that of the more sophisticated models.

To calculate the cell temperature the semi-empiric approach of [26] is used in this study. The first term describes the temperature of the photovoltaic module with the effective irradiation $G$, the wind speed $v_{\text {wind, }}$, the ambient temperature $T_{a}$ and the empirical parameter $a$ and $b$ which describe the mounting system and module technology. The cell temperature can be calculated by using an empirical temperature difference $\Delta T$ and the effective irradiation. The empiric parameters used here refer to a glass/cell/polymer sheet module type with an open rack mounting system [26].

$$
T_{c}=\left(G \cdot \exp ^{a+b \cdot v_{W i n d}}+T_{a}\right)+\Delta T \cdot \frac{G}{1000}
$$

To include the proceeding degradation of a photovoltaic module, an annual degradation rate of the peak-power of $0.5 \%$ is assumed here, corresponding to [27]. All relevant parameters and constants used in the photovoltaic model can be found in Table A. 1.

\subsubsection{Battery model}

Batteries are strongly non-linear, electro-chemical systems. According to [28] the main internal influencing factors are DoD/State of Charge $(\mathrm{SoC})$, State of Health $(\mathrm{SoH})$, internal resistance, self-discharge, design 
parameters, etc. The main external factors are temperature, C-rate, and operating history (e.g. cycles or rest period).

The aging of the battery leads to loss of capacity primarily due to loss of active material and reduction of power performance due to rising internal resistance [29]. The aging is mainly dominated by the charging/discharging cycles (cycle aging) and the rest periods (calendrical aging) [30].

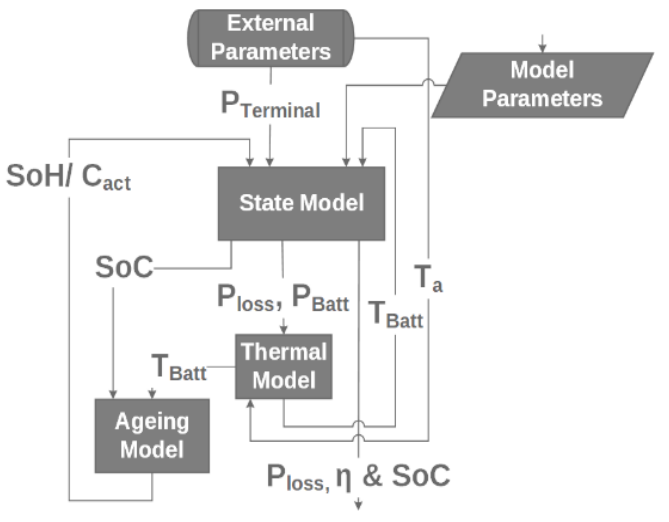

Figure 2 High-level battery model block diagram.

A large variety of models for Lithium-based battery cells can be found in the literature. They vary strongly in the influencing factors included and their field of application. Most models used in energy and electricity system simulations are structured as seen in Figure 2, which is based on [31].

In this study, the above-mentioned topology is adapted. The central state model calculates the energy dissipation during the charging and discharging process (reflected by $P_{\text {loss }}$ the battery power loss due to energy dissipation, which is the difference between the terminal power $\mathrm{P}_{\text {Terminal }}$ and the battery power $P_{\text {Batt }}$ ), usable battery capacity with charging and discharging limits and SoC for every simulation step. The thermal model determines the temperature of the battery cell. The aging model defines the battery capacity over the simulation period by determining the loss of capacity per time step (the SoH-dependent battery capacity is represented by $C_{\text {act }}$ ).

\subsubsection{State model}

The state model is essentially influenced by the cell temperature, C-rate, SoC, self-discharge, and battery capacity. At a temporal resolution of one minute, it can be assumed that the electrical short-term dynamics of battery cells, which in equivalent circuit models (ECM) are usually be described as resistor-capacitor circuits, can be neglected.

The parametrization of the state model is based on the open-access datasheet of the Thunder Sky Winston LFPcell WB-LYP4OAHA [32]. The charge and discharge curves show the terminal voltage $\mathrm{V}_{T}$ of the battery over the SoC at different $\mathrm{C}$-rates $(0.5 \mathrm{C}, 1.0 \mathrm{C}, 2.0 \mathrm{C}, 3.0 \mathrm{C})$ and temperatures $\left(55^{\circ} \mathrm{C}, 25^{\circ} \mathrm{C}, 0^{\circ} \mathrm{C},-25^{\circ} \mathrm{C},-45^{\circ} \mathrm{C}\right)$. For the mathematical formulation, the data is fitted with the following equation as used in [33]. Thereby, a to $f$ are the fitting parameters.

$$
V_{T}(S o C)=-a \cdot S o C+b+c \cdot\left(\frac{1}{f+S o C}\right)-d \cdot \exp ^{-e *(1-S o C)}
$$

Due to the different existing definitions, for the fitting of charge and discharge curves, the SoC of $0 \%$ is defined as the minimal value at the cut-off voltage $(2.8 \mathrm{~V})$ and the nominal C-rate $(0.5 \mathrm{C})$ and temperature $\left(25^{\circ} \mathrm{C}\right)$. In addition, discharge curves are restricted to the cut-off voltage $(4.0 \mathrm{~V})$.

The battery state model describes the energy dissipation during the charge and discharge process considering the influencing factors battery temperature and C-rate. Therefore, a simple equivalent circuit is used as described in [31]. It is assumed that the power-dependent losses only occur at the internal resistance $\mathrm{R}_{\text {int. }}$. Nonetheless, a distinction is made between charging and discharging. To represent the temperature-dependent energy dissipation, an additional resistance is added in series to the circuit. Since an energy-based simulation is conducted, the ECM should be understood as a combination of energy losses rather than electrical resistances.

The internal resistance can be determined by the terminal voltages at two different currents $I_{1}$ and $I_{2}$. Applying the Ohmic law, the power-dependent energy dissipation during charge and discharge can be defined through the battery efficiency:

$$
R_{\text {int }}=\frac{V_{T}\left(\operatorname{SoC}, I_{1}\right)-V_{T}\left(\operatorname{SoC}, I_{2}\right)}{I_{1}-I_{2}}
$$


$\eta_{\text {charge/discharge }}=\frac{P_{T}-\left(I^{2} \cdot R_{\text {int }}\right)}{P_{T}}$

The determined resistance for the different charge/discharge curves shows no clear SoC-dependent trend. Also, the charging strategies make the analysis of this SoC-dependent behavior unfeasible. For this reason, only the SoC-independent mean values of the resistances are used, compare Table 1.

Table 1 Modeled mean internal resistance of the battery cell and their standard deviation.

\begin{tabular}{llll}
\hline & Unit & Charging & Discharging \\
\hline Mean internal resistance & {$[\Omega]$} & 0.0019 & 0.0025 \\
Abs. standard deviation & {$[\Omega]$} & \pm 0.0009 & \pm 0.0014 \\
Rel. standard deviation & {$[-]$} & \pm 0.461 & \pm 0.535 \\
\hline
\end{tabular}

With the assumption of mean internal resistance values and the parametrized charge and discharge curves at different C-rates, linear correlations for the C-rate dependent battery charge and discharge efficiency can be determined. Inside the battery model, the C-rate is defined as $C$-rate $=P_{T} \cdot C_{n o m}{ }^{-1}$ with the battery nominal capacity $\mathrm{C}_{\text {nom. }}$.

$$
\begin{aligned}
& \eta_{\text {discharge }}(C-\text { rate })=1-0.02803 \cdot C \text {-rate } \\
& \eta_{\text {charge }}(C-\text { rate })=1-0.02115 \cdot C \text {-rate }
\end{aligned}
$$

To determine the thermally induced energy dissipation a relative voltage drop $\Delta \mathrm{V}$ per temperature deviation $\Delta \mathrm{T}$ from the reference temperature $T_{\text {ref }}=25^{\circ} \mathrm{C}$ is defined. This is in accordance with the determination of the internal resistance.

$$
\frac{\Delta V}{\Delta T}=\frac{V\left(T_{1}\right)-V\left(T_{r e f}\right)}{T_{1}-T_{r e f}}
$$

Analog to the C-rate calculation a temperature-dependent efficiency is determined with mean values of these relative voltage drops at nominal current flows and the temperature difference. The mathematical correlation derives as follows. It is important to note that the temperature unit used is ${ }^{\circ} \mathrm{C}$ and that the model only shows reasonable characteristics in the interpolated region between the used data points $\left(-45^{\circ} \mathrm{C}\right.$ to $\left.+55^{\circ} \mathrm{C}\right)$.

$$
\eta(T)=1-\left(\frac{T-T_{r e f}}{3,6}\right) \cdot\left(-1.260 \cdot 10^{-7} \cdot T^{3}-1.315 \cdot 10^{-6} \cdot T^{2}-3.748 \cdot 10^{-4} \cdot T-6.209 \cdot 10^{-3}\right.
$$

The total energy dissipation during charge/discharge processes derives from a simple multiplication of these two losses.

$$
P_{\text {loss }, \text { total }}=P_{T} \cdot \eta(C-\text { rate }) \cdot \eta(T)
$$

Furthermore, the battery state model determines the actual SoC in every simulation step by a simple energy balance using an off-line book-keeping method. The charging and discharging terminal power $\mathrm{P}_{\mathrm{T}}$, power and

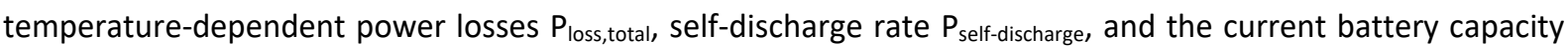
$\mathrm{E}_{\text {actual }}$ depending on the $\mathrm{SoH}$ and the $\mathrm{SoC}$ of the previous time step are taken into account.

$$
\operatorname{SoC}(t)=\operatorname{SoC}(t-1)+\frac{\left(P_{T}-P_{\text {loss }, \text { total }}-P_{\text {self-discharge }}\right) \cdot \Delta t}{E_{\text {actual }}}
$$

Most energy-based simulations of power supply systems define a constant maximum DoD. For the sake of simplicity, this is an acceptable approach, however, this does not reflect the real-life battery (control) behavior. The BMS usually defines a maximum discharge and charge voltage, at which the charging/discharging is stopped. The DoD-voltage correlation is dependent at least on the cell temperature, terminal power, and SoH. To integrate this dynamic factor into energy-based simulations (and not only in electrical) a new, flexible and energy-based DoD-model is proposed.

The end-of-charge ( $\mathrm{SoC}_{\mathrm{cut}}$ off, $\left.\mathrm{CH}\right)$ and end-of-discharge SoCs $\left(\mathrm{SoC}_{\mathrm{cut}}\right.$ off, $\left.\mathrm{DCH}\right)$ are extracted from the respective fitted charge and discharge curves for different C-rates and temperatures. On this basis, the following correlations can be generated. Since no temperature-dependent data is provided by the used battery datasheet for the charge 
case, it is neglected in this study but can be integrated into the model for other batteries if datasheet values are available. It is further assumed that for the temperature-dependent discharge boundary the BMS can adapt the end-of-discharge voltage for low temperatures (especially under $0{ }^{\circ} \mathrm{C}$ ) below the nominal value of $2.8 \mathrm{~V}$.

$$
\begin{aligned}
& \operatorname{SoC}_{\text {cut of }, C H}\left(P_{T}\right)=1.1410-0.000225 \cdot C \text {-rate } \\
& \operatorname{SoC}_{\text {cut of } f, D C H}\left(P_{T}\right)=-0.0210+0.000352 \cdot C \text {-rate } \\
& \operatorname{SoC}_{\text {cut of } f, D C H}(T)=-0.2536 \cdot \exp ^{0.153657 \cdot(80+T)}+0.7318
\end{aligned}
$$

To consider both influencing factors (temperature and C-rate) at the discharging process, they need to be normalized to the reference point (here: $25^{\circ} \mathrm{C}$ and $0.5 \mathrm{C}$ ). By this, they can be added up, as shown in the following equation.

$$
\operatorname{SoC}_{\text {cut of } f, D C H}\left(P_{T}, T\right)=\operatorname{SoC}_{\text {cut off }, D C H}\left(0.5 C, 25^{\circ} C\right)+\frac{\operatorname{SoC}_{\text {cut off }, D C H}\left(P_{T}\right)}{S o C_{\text {cut off }, D C H}\left(0.5 C, 25^{\circ} C\right)}+\frac{\operatorname{SoC}_{\text {cut off }, D C H}(T)}{S o C_{\text {cut off }, D C H}\left(0.5 C, 25^{\circ} C\right)}
$$

\subsubsection{Thermal model}

Many thermal battery models are based on the heat balance equation of [34]. This consists of the Ohmic losses, reaction enthalpy, reaction heat of side reactions, and mixing enthalpy. Due to [35] the reaction enthalpy, due to [36] the reaction heat of side reactions, and due to [37] the mixing enthalpy are negligible for long-term energy system simulations of several months or years. This simplifies the equation to the ohmic losses.

In addition, the convective heat exchange is included in the model. Hereby, the battery temperature of every time step is defined through the following equation by the battery's convective heat transfer coefficient $h$, surface $A$, mass $m_{\text {battery }}$ and average heat capacity $c_{p, \text { battery }}$.

$$
T(t+1)=\frac{P_{\text {loss,total }}-h \cdot A \cdot\left(T(t)-T_{\text {environment }}(t)\right) \cdot d t}{m_{\text {battery }} \cdot c_{p, \text { battery }}}+T(t)
$$

\subsubsection{Aging model}

The aging during the rest periods is mainly influenced by the rest time, the square root of the temperature, and the SoC [30], [38]. However, the cycle aging is primarily influenced by the current, charge throughput, and average temperature [30], [39]. In this model, both aging effects and their impact on the loss of capacity are considered.

The generalized model by Wang et al. for LFP-battery-cells is used to determine the capacity loss by cycle aging [40]. It calculates the relative capacity loss in dependency of the C-rate, temperature, and charge throughput in Ah. The empiric correlation is shown below with the empiric factor $B$, the universal gas constant $R$, and the battery temperature $\mathrm{T}$.

$$
\frac{d Q_{\text {loss }, \text { cycle }}}{d t}=B \cdot \frac{31700+370.3 \cdot C-\text { rate }}{R \cdot T} \cdot A h^{0.55}
$$

For a dynamic and time-discrete simulation, further adaptions are necessary. The charge throughput Ah by Wang et al. describes the number of half-cycles which is defined as a relative value and is adopted through the product of battery C-rate and length of the timestep. The defined empiric factor B is dependent on the C-rate, though in [40] only exemplary values for certain C-rates are specified. Therefore, the values for factor B are fitted to a $3^{\text {rd }}$ order-polynomic correlation depending on the C-rate.

$$
B=-47,84 \cdot C-\text { rate }^{3}+1215 \cdot C-\text { rate }{ }^{2}+9419 \cdot \text { C-rate }+36040
$$

The relative capacity is then integrated into the aging model to determine the capacity loss and current battery capacity at every time step. Further details are provided in [40].

Many aging models for calendrical aging of lithium battery cells are based on experiments with constant stress factors (e.g. in [41]) and are therefore not feasible for dynamic conditions. However, Grolleau et al. developed and tested a model, which includes changing storage conditions [38]. This model is adopted here, for which the correlation of the relative capacity loss is shown in the following equation with battery temperature $\mathrm{T}$ and the nominal battery capacity $\mathrm{C}_{\text {nom. }}$. 


$$
\frac{d Q_{\text {loss, calendric }}}{d t}=k(T, S o C) \cdot\left(1 \cdot \frac{Q_{\text {loss }}(t)}{C_{\text {nom }}}\right)^{-\alpha(T)}
$$

The empiric factor $\alpha$ is dependent on the battery temperature, even though in [38] only exemplary values are specified. Therefore, the proposed values are fitted by the following equation.

$$
\alpha(T)=e^{-(0.2 \cdot 60-\log (4))+(T \cdot 0,2)}+3
$$

The term $Q_{\text {loss }}(t) / C_{n o m}$ is the fractional capacity loss at time $t$, while the kinetic term $k(T, S o C)$ is further defined in [38]. All relevant parameters and constants used in the battery model can be found in Table A. 2.

\subsubsection{Electronic model}

In literature, two different approaches are commonly used to model power electronics, ECM (e.g. in [42]) and numerical models. A $2^{\text {nd }}$-order-polynomial seems appropriate for modeling the power losses as a function of input or output power, as described in [43]. The attempt is made to achieve a manufacturer datasheet parametrization. It should thereby be noted that these data differ greatly from manufacturer to manufacturer, although the provided data is in general insufficient for modeling the energy losses properly.

In the following, a mathematical model based on a $2^{\text {nd }}$-order-polynomial by [43] is used. The energetic efficiency $\eta$ based on the output power can be calculated as follows.

$$
\eta=\frac{P_{\text {out }}}{P_{\text {out }}+\left(p_{\text {self }}+v_{\text {loss }} \cdot P_{\text {out }}+r_{\text {loss }} \cdot P_{\text {out }}\right)}
$$

The second term of the dividend refers to the power loss whereby $p_{\text {self }}$ refers to the non-performance-related self-consumption, vloss to the voltage losses over diodes and transistors, and $r_{\text {loss }}$ to the ohmic losses due to the current flow. The used parameters and nominal efficiencies for the electronic components are shown in Table A 3. These values either refer to literature or are based on numerical fittings from the manufacturer's datasheets. In terms of numerical fitting, negative identified parameters are possible due to the least square method used. In this work, no gradual aging effects are considered for power electronics. This matches common practice in literature (e.g. in [44], [45]). Analogous to these works, the total lifetime for the inverters and charge controllers is estimated at ten years, and five years for the battery management system. The same model is used for all power electronics considered in this study.

\subsubsection{Load Profile}

The load profile is a crucial part of energy-based economic analyses (cf. [46]), in particular for systems with fluctuating power generation and demand as they have to be balanced by an energy storage system. Nevertheless, creating a representative load profile is by no means trivial. For off-grid power supply systems, the data basis is especially weak [47]. The aggregated, normalized German household load curve of [17] with a 1minute resolution was used in this study. This data has also been tested for plausibility. It must be noted that the local socio-economic situation (and with this the load profile) of households varies greatly between regions with poor energy connection to the electrical grid and the situation in Germany. Nonetheless, it serves as a general point of comparison. However, it is accommodated that most households in off-grid regions have lower yearly energy demands compared to Germany. For this reason, this load profile is scaled down to 2,154 kWh·a ${ }^{-1}$, which corresponds to the yearly electric energy demand of a household in Pakistan [48], lies in the same order of magnitude as that of Uganda [49] and the Tier 4 of the Multi-Tier-Framework of The World Bank [50].

\subsubsection{Meteorological data}

Another main influencing factor which was analyzed for this research is that of system location, which is concomitant with prevailing weather conditions. The following exemplary locations have been analyzed to compare different climates:

- Temperate climate: Berlin, Germany $\left(52.589^{\circ}, 13.271^{\circ}\right)$

- Tropical climate: near Lake-Victoria Kenya $\left(-0.641^{\circ}, 34.099^{\circ}\right)$

- Arid climate: near Isfahan, Iran $\left(32.342^{\circ}, 52.012^{\circ}\right)$

- Mediterranean climate: Lykia, Turkey $\left(36.484^{\circ}, 29.131^{\circ}\right)$

- Continental climate: near Achamayli, Usbekistan $\left(43.000^{\circ}, 59.000^{\circ}\right)$ 
To follow the open-source approach of this work, the 1-minute temporal resolution data of MINES ParisTech and Transvalor Dpt SoDa was used, which is validated in [51]. The data for the period of 1.2.2004 - 31.12.2005 is available on their homepage and free of charge [52]. Data on ambient air temperature, humidity, and wind speed is based on the MERRA database provided by the NASA Goddard Space Flight Center [53]. An overview of the climate data for the considered locations is presented in Table A. 4.

\subsection{Economic model}

The investment costs have the main share of the overall costs of renewable power supply systems. However, these differ greatly depending on the location, system size, or type of usage [54]. This uncertainty is especially large in the off-grid sector. In several regions, the prices can be up to 12-times as high as in others [55]. In respect to the generic approach, general economic assumptions for the investment costs (cc) of the system components, operation and maintenance (omc), and balance of system costs are made according to literature references. The economic assumptions are summarized in Table A. 5. Data on LFP battery investment cost scenarios were lacking in general, although more readily available within the mobility sector. For this reason, pricing data was used from the latter. The time-dependent investment cost function is estimated by a curve fit based on the data provided by [56]-[60], where $t$ is the time in years.

$$
c c_{B a t}(t)=240+\exp ^{(-0.24562 \cdot t+500)}
$$

\subsection{Simulation}

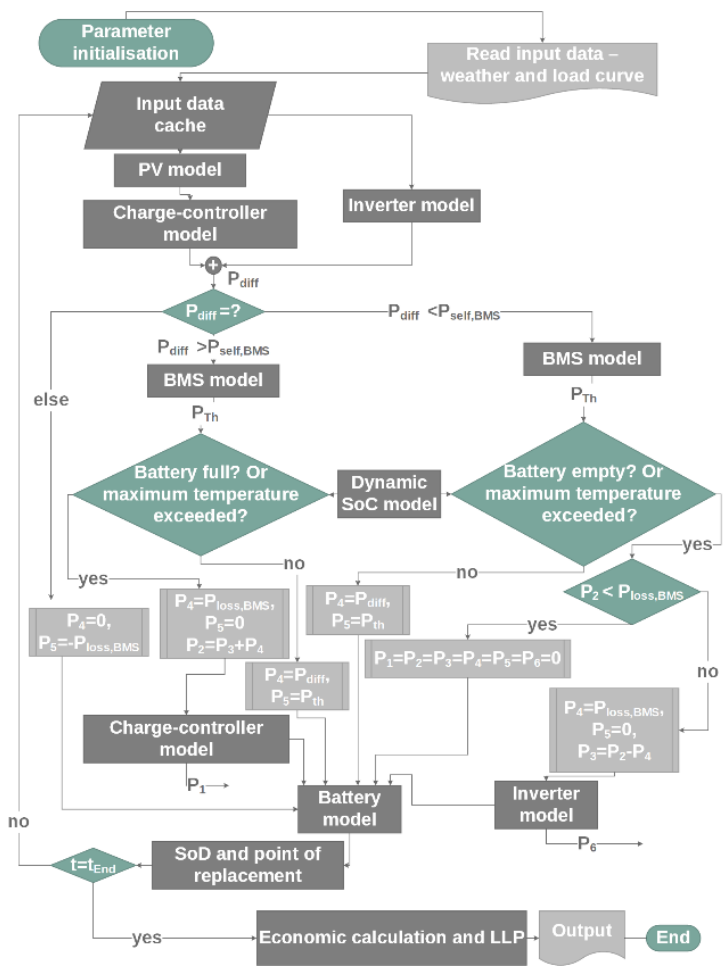

Figure 3 Simulation flowchart. $P_{\text {self,BMs }}$ indicates the BMS energy self-consumption and $\mathrm{P}_{\text {loss, } \mathrm{BMS}}$ the $\mathrm{BMS}$ power loss due to energy dissipation.
The modeling tool is written in the high-level language Python $^{\mathrm{TM}}$ 3.6. (Anaconda ${ }^{\circledR}$ 4.3.1) and published under the open-source license LGPL-3.0 on Github ${ }^{1}$.

The developed simulation follows a time-discrete, deterministic, and, apart from the cost functions of the single components, likewise time-invariant approach. Figure 3 presents the simulation flowchart. The procedure starts with the initialization of technical parameters and the input of timeseries data. Consequently, the component models are calculated for every simulation timestep. This includes especially the battery charging and discharging process after determining the power flow $\mathrm{P}_{\text {diff }}$ (the difference between $P_{2}$ and $P_{3}$ ) at the central power knot of the system (see Figure 1). Dependent on a positive or negative value of $P_{\text {diff }}$ the battery is charged or discharged, respectively. Therefore, the battery charge and discharged boundaries are determined to examine if the battery can handle the requested power flow. Finally, the State of Destruction (SoD) of all components is analyzed and in case of reaching the end of life criteria components are replaced. After the iteration process, the objective functions are calculated. The power flow numbering follows the denotation introduced in Figure 1.

For the sizing process, technical and economical objective functions are used. The common key figure Levelized Costs of Electricity (LCOE) is used for economic quantification. As shown in the following equation the LCOE is calculated by the ratio of the Annual Levelized Cost Flows (ATLCC) to the used amount of electric energy $E_{\text {total }}$ according to [15]. The ATLCC are calculated by the annuity method including the annuity of investment costs $\left(A_{c c, k}\right)$, operation and maintenance costs $\left(A_{o m c, k}\right)$, replacement costs $\left(A_{r c, k}\right)$, and residual costs $\left(A_{r v, k}\right)$ of all components $k$ according to [61]. The residual costs are the replacement costs multiplied with (1-SoD), which is one for new components and zero for end-of-life components.

\footnotetext{
${ }^{1}$ The corresponding repository can be found at https://github.com/josch-a/energysimulation
} 


$$
L C o E=\frac{A T L C C}{E_{\text {total }}}=\frac{\sum_{k} A_{c c, k}+A_{o m c, k}+A_{r c, k}+A_{r v, k}}{E_{\text {total }}}
$$

The security of power supply is a major parameter for describing the efficiency and performance of an off-grid power supply system in a technical sense. Thereby, the required security has a strong influence on economics [62]. Nevertheless, there is no generally accepted performance figure, [63]. In [15] different quantification figures are discussed. Due to the generic approach of this research and the concomitant low focus on special user behavior or socio-economic factors, the rather simple Loss of Load Probability (LLP) method is used here. It is based on the amount of energy not supplied, which is the balance of demand and the supplied load in the period under review [15]. Thereby, $\mathrm{P}_{\text {Load demand }}(\mathrm{t})$ and $\mathrm{P}_{\text {load supplied }}(\mathrm{t})$ are the average loads of the corresponding simulation step. To convert this absolute value into a relative one it is normalized by the load demand of the simulation period $\tau$.

$$
L L P=\frac{\sum_{t=1}^{\tau}\left(P_{\text {load demand }}-P_{\text {load supplied }}\right) \cdot \Delta t}{\sum_{t=1}^{\tau} P_{\text {load demand }} \cdot \Delta t}
$$

\subsection{Optimization}

Multi-objective optimization aims to identify the optimal solution for a multidimensional problem with often conflicting objective functions. In the case of system sizing, the optimization seeks to identify optimal system configurations and capacities of the components for a given use-case. The set of Pareto-optimal solutions consists of the non-dominated system configurations inside the objective space (Pareto-front). Decision variables inside the decision space define the system configuration. The Pareto-front will give the designer of such nano/micro-off-grid power supply system the capability to choose the system sizes regarding the requirements of the use case.

Here, a multi-objective optimization is conducted to generate the Pareto-optimal set of solutions considering the economic objective function Levelized Cost of Energy and the technical objective function Loss of Load Probability as defined previously. The decision variables are the installed photovoltaic peak power, battery capacity, and nominal inverter power. The Non-Sorting-Genetic-Algorithm-II (NSGA-II), a frequently used algorithm [10], is implemented according to Deb et al. [64]. The good performance of the used NSGA-II is validated in [64]. The algorithm follows the basic procedure of evolutionary algorithms and selects the preferred options according to the rank of the non-dominated front and the crowding distance. Standard values according to [64] are used for the generator, selector, and variator. The set-up values for parameterizing the NSGA-II algorithm can be found in Table A. 6.

\section{RESULTS}

This section presents the application of the developed modeling tool for the multi-objective optimization of a nano/micro-off-grid power supply system. Influencing factors on the set of Pareto-optimal solutions (Paretofront) with the performance in the objective functions LCoE and LLP are analyzed and presented in the figures. The absolute numbers of decision variables are not considered.

The general shape of all Pareto-fronts meets the author's expectation and is comparable to sets presented in the literature (e.g. in [9]). The obtained fronts in this research show a good solution distribution and extent of the Pareto-front according to [10]. Nevertheless, a detailed analysis of the optimization algorithm performance is not the objective of the presented study. 


\subsection{Influence of location}

In Figure 4 the optimization results are shown for the different considered locations. The general run of the Pareto-fronts is similar and the curves are well distinguishable from each other. It appears that the systems in

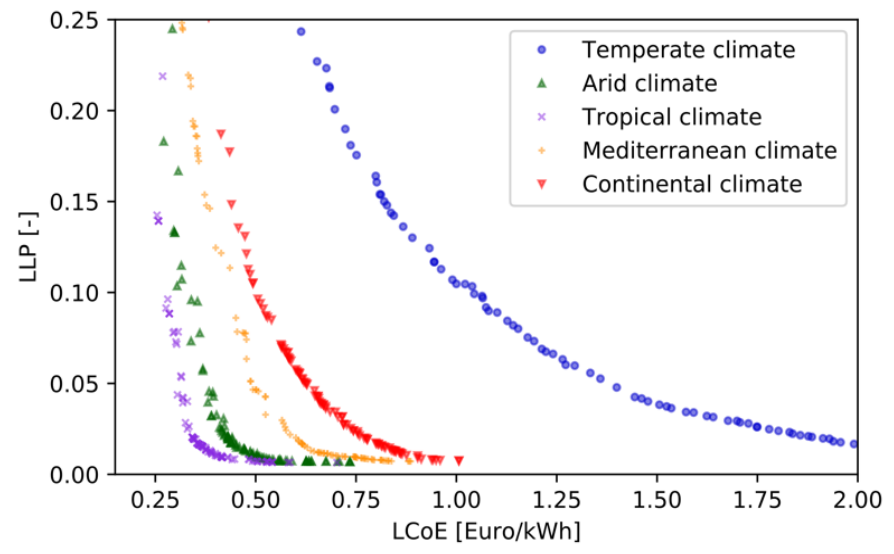
the temperate climate are the most expensive ones, while the results for the other regions are more related to one another. The temperate climate location has 2 to 5 times higher costs for the same LLP of $1 \%$ to $12 \%$ compared to the tropical climate, which shows the lowest LCoEs. The cost difference decreases with an increase of the LLP for all considered climates. When evaluating the common values of two Pareto-fronts, a linear correlation between the temperate climate and all other considered locations can be identified.

Figure 4 Comparison of the Pareto-optimal optimization results of 1-year simulation with a temporal resolution of one minute for the considered locations.

The fact that the results for different locations are well distinguishable from one another shows that the ratio of energy input and demand has a distinct impact on the objective functions since the latter stays constant in this simulation and just the energy input distinctively differs between the different locations. In comparison to irradiation, the temperature has a minor influence on the results. This can be explained by the fact that the results of different locations can be ordered by increasing irradiation, however not by decreasing temperatures (see Table A. 4). This is as well supported by other data sources like the Global Solar Atlas [65]. However, the results do not correlate in direct proportion to the irradiation, which reflects the minor influence of temperature.

\subsection{Influence of temporal resolution}

The optimization results of simulations with a temporal resolution of one minute and one hour for the different considered locations are shown in Figure 5. This reveals that the general run of the Pareto curves is similar regardless of the simulation temporal resolution, although the Pareto-fronts for the hourly resolution

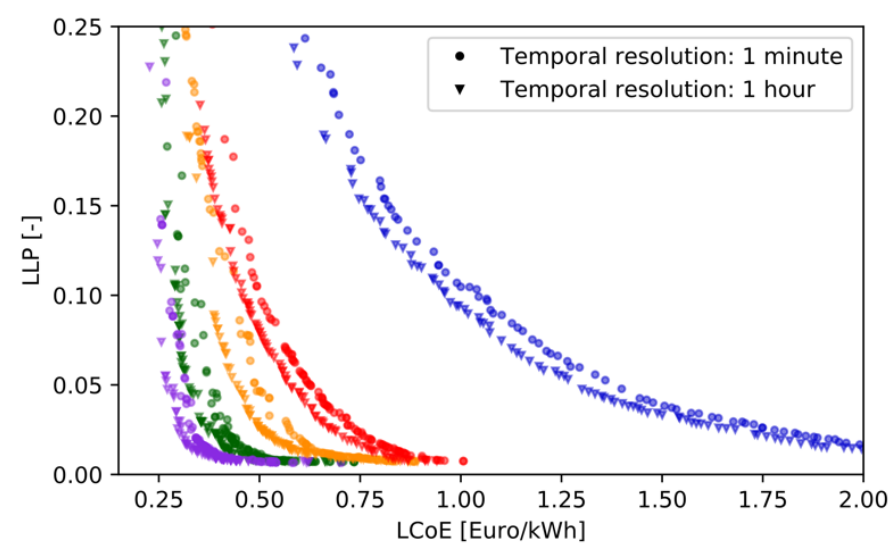

Figure 5 Comparison of the Pareto-optimal optimization results of 1-year simulation of the considered locations for a temporal resolution of one minute and one hour. optimization are shifted towards lower LCoEs at a constant LLP. The LCoEs for hourly optimization are in the range of $5 \%$ to $15 \%$ under the optimization based on a temporal resolution of one minute at a common LLP for all considered locations. For LLPs above $1 \%$, the mean LCOE deviation is quite constant between $6 \%$ and $9 \%$

The expectations of the authors and the literature in [17]-[19] and [22] regarding a strong influence of the temporal simulation resolution on the evaluation of photovoltaic systems, as well as the fact that lower temporal resolution leads to overly optimistic expectations, are supported by these results. 


\subsection{Influence of simulation period}

The influence of the simulation period is studied by comparing 1-year and 20-year simulations with a temporal resolution of one minute. Single points of a 1-year Pareto-front for the continental climate have been used to conduct a 20-year simulation. The decision variables of the pair of objective function results ( $L C O E 0.44 € \cdot k W h^{-1}$; LLP $15 \%$ ), (LCoE $0.58 € \cdot \mathrm{kWh}^{-1}$; LLP $6 \%$ ) and (LCoE $0.90 € \cdot \mathrm{kWh}^{-1}$; LLP $1 \%$ ) are chosen exemplarily, as shown in

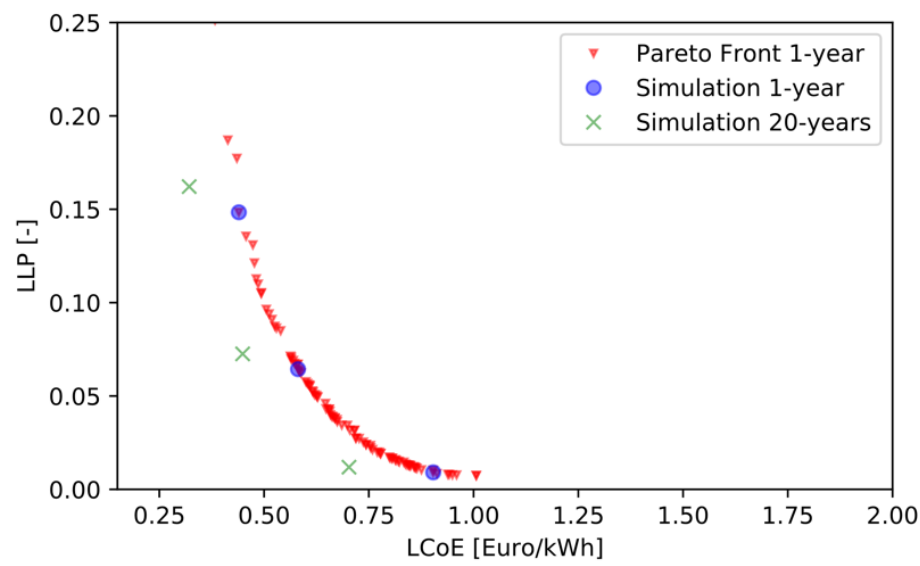

Figure 6 Comparison of 1-year and 20-year simulation for the continenta climate.
Figure 6. The results for the LLP and LCOE for a 20-years simulation are shown for all three considered designs. The LLP for long-term simulations is 9$31 \%$ higher than for the short-term simulations. The relative difference increases for smaller systems with higher LLPs. Despite the higher LLP, the results of long-term simulations consistently show a lower LCoE, hence the lower amount of supplied energy has no significant influence on the relative costs. The $\mathrm{LCOE}$ deviation between short-term and long-term lies within the range of $22-27 \%$ for the chosen system configurations.

The higher LLP observed for long-term simulations in comparison to the short-term meets the expectations, because the influence of degradation of single components is much larger for long-term simulations. This is based on the dissimilar non-linear aging processes of the different system components over the analyzed simulation period. Thus, the real usable power and capacity are distinctly lower and the loss of load probability increases, accordingly. This result highlights the need to integrate the component degradation and replacement costs, especially for batteries, inside the simulation model [12]-[14].

The quite constant decrease in costs for long-term simulations is contrary to the technical influences which are mainly represented by the LLP. Because of that, the reason for it is assumed to lie within the economic model, which integrates decreasing replacement investment costs of the components that must be replaced during the simulation period. In particular, the assumption of significantly decreasing investment costs of the battery corresponding to the prospects in literature must be considered. The influence of the simulation period on the annuity calculation has been balanced through a theoretical residual cost function which correlates exactly with the SoD. This leads to equal annuities of short-time and long-time simulation horizons unless no replacement investment takes place.

In general, it can be stated that the 1-year simulation leads to significantly more pessimistic results regarding economics and delivers more optimistic results in terms of the security of supply than the 20-year simulation. Nevertheless, a 20-year simulation seems to be the more suitable approach, because it assumes the reduction of the investment costs and includes the degradation of the components which is more realistic for a real-life application in the field.

\section{CONCLUSION}

In the scope of this work, an open-source modeling tool for the simulation and optimization of renewable nano/micro-off-grid power supply system was developed. The modeling approach follows key requirements for a general and adaptive model structure to make the tool generic and adaptable to various use cases and applications. It integrates relevant dynamic behavior, which occurs in the chosen temporal resolution and aging effects.

Using the two-objective-optimization algorithm NSGA-II and the objective functions LLP and LCoE the influence of the following factors on the set of Pareto-optimal solutions is examined and the practical application of the modeling tool is presented. 
- System location by comparing the result for simulations with weather data of five representative locations shows the difficulty of designing generic system sizes for multiple target markets.

- Temporal resolution of input data (weather and load profile) by comparing a resolution of one minute and one hour for the different considered locations, lower temporal resolution leads to overly optimistic results.

- Simulation period by comparing 1-year and 20-year simulations with a temporal resolution of one minute at continental climate, shorter simulation periods lead to overly pessimistic results.

Finally, we conclude with the following key findings:

- A distinct influence on the Pareto-front could be identified for all analyzed factors.

- The system location dictates the technical and economic performance through climate conditions.

- The influence of the temporal resolution and the simulation period on the LCOE and LLP is significant and should be considered in the design process of such nano/micro-off-grid power supply system regarding the computation time needed.

Due to the generic approach of this work and the wide range of compared input data, it is limited in its significance for specific detailed real-life systems, but a relative comparison of the reasonable range of the examined influencing factors can be done. This makes it also difficult to benchmark it to existing work in a quantitative manner. However, it is shown that the influence of the analyzed factors is distinct, and the literature review above has shown that it is nevertheless neglected in most of the research articles to date. This shows the qualitative significance of these results. Because this work intentionally only uses datasheet and open-access data, it is limited in the variability of input data sources. Besides, it is only focusing on AC connected photovoltaicbattery systems, even though the strong influence of the climate on costs and reliability shows the need to include further sources of energy.

Future work with the developed open-source tool comprises the advancement of the battery model with other battery technologies as lead-acid and its application for decision support of optimal design and technology choice for Solar Home Systems as an example of pico-off-grid systems. In the long-term, the tool shall be enhanced with other renewable electricity generation and storage technologies for the modeling of self-sufficient energy systems. Also, the comparison with real-life system data based on different design approaches should be considered to underline the need for long-term and high temporal resolution simulations for the system design.

\section{ACKNOWLEDGEMENTS}

This research did not receive any specific grant from funding agencies in the public, commercial, or not-for-profit sectors. 


\section{APPENDIX}

Table A. 1 Parameter for the photovoltaic model.

\begin{tabular}{lllll}
\hline Parameter & Description & Unit & Value & Source \\
\hline$\gamma_{0}$ & Power model: Temperature coefficient & $\mathrm{W} \cdot \mathrm{K}^{-1}$ & -0.5 & - \\
$\mathrm{G}_{\mathrm{ref}}$ & Power model: Effective irradiation under STC & $\mathrm{W} \cdot \mathrm{m}^{-2}$ & 1000 & - \\
$\mathrm{a}$ & Thermal model: Empirical coefficient & - & -3.56 & {$[26]$} \\
$\mathrm{b}$ & Thermal model: Empirical coefficient & - & -0.075 & {$[26]$} \\
$\Delta \mathrm{T}$ & Thermal model: Empirical coefficient & ${ }^{\circ} \mathrm{C}$ & 3 & {$[26]$} \\
\hline
\end{tabular}

Table A. 2 Parameter for battery model.

\begin{tabular}{lllll}
\hline Parameter & Description & Unit & Value & Source \\
\hline $\mathrm{P}_{\text {self-discharge }}$ & Self-discharge rate & $\% \cdot \mathrm{s}^{-1}$ & $9.04 \cdot 10^{-7}$ & {$[32]$} \\
$\mathrm{k}_{\mathrm{A}}$ & Chemical rate constant A & - & $4.39 \cdot 10^{-5}$ & {$[38]$} \\
$\mathrm{k}_{\mathrm{B}}$ & Chemical rate constant B & - & $1.01 \cdot 10^{-3}$ & {$[38]$} \\
$\mathrm{E}_{\mathrm{aA}}$ & Activation energy A & $\mathrm{kJ} \cdot \mathrm{mol}^{-1}$ & 182.0 & {$[38]$} \\
$\mathrm{E}_{\mathrm{aB}}$ & Activation energy B & $\mathrm{kJ} \cdot \mathrm{mol}^{-1}$ & 52.1 & {$[38]$} \\
$\mathrm{R}$ & Universal gas constant & $\mathrm{J} \cdot \mathrm{mol}^{-1} \cdot \mathrm{K}^{-1}$ & 8.314 & {$[40]$} \\
\hline
\end{tabular}

Table A. 3 Model parameter of electronic components.

\begin{tabular}{llllll}
\hline Component & $p_{\text {self }}$ & $v_{\text {loss }}$ & $r_{\text {loss }}$ & $\eta_{\text {nominal }}$ & Source \\
\hline Inverter & 0.0072 & 0.0000 & 0.0375 & 0.9800 & {$[25]$} \\
MPPT & $4.08 \cdot 10^{-3}$ & $6.07 \cdot 10^{-3}$ & 0.0228 & 0.9750 & {$[66]$} \\
BMS & $9.93 \cdot 10^{-5}$ & $-0.0025 \cdot 10^{-16}$ & 0.0310 & 0.9720 & -2 \\
\hline
\end{tabular}

Table A. 4 Climate data of considered locations (own calculations based on [52], [53]).

\begin{tabular}{llllllll}
\hline Parameter & Unit & $\begin{array}{l}\text { Temperate } \\
\text { climate }\end{array}$ & $\begin{array}{l}\text { Tropical } \\
\text { climate }\end{array}$ & $\begin{array}{l}\text { Arid } \\
\text { climate }\end{array}$ & $\begin{array}{l}\text { Alpine } \\
\text { climate }\end{array}$ & $\begin{array}{l}\text { Mediterranean } \\
\text { climate }\end{array}$ & $\begin{array}{l}\text { Continental } \\
\text { climate }\end{array}$ \\
\hline $\mathrm{T}_{\max }$ & $\mathrm{K}$ & 306 & 307 & 314 & 299 & 307 & 320 \\
$\mathrm{~T}_{\min }$ & $\mathrm{K}$ & 262 & 289 & 266 & 246 & 275 & 249 \\
$\mathrm{~T}_{\text {mean }}$ & $\mathrm{K}$ & 282 & 297 & 289 & 275 & 291 & 286 \\
$\mathrm{~T}_{\text {Std. deviation }}$ & $\mathrm{K}$ & 9 & 3 & 11 & 10 & 7 & 15 \\
$\mathrm{G}_{\max }$ & $\mathrm{Wh} \mathrm{m} \mathrm{m}^{-2}$ & 921 & 1140 & 1091 & 1128 & 1040 & 977 \\
$\mathrm{G}_{\text {annual }}$ & $\mathrm{kWh} \mathrm{m}^{-2} \mathrm{a}^{-1}$ & 1064 & 2317 & 2065 & 1616 & 1713 & 1574 \\
$\mathrm{G}_{\text {Std. deviation }}$ & $\mathrm{Wh} \mathrm{m} \mathrm{m}^{-2}$ & 203 & 356 & 323 & 259 & 303 & 271 \\
\hline
\end{tabular}

Table A. 5 Assumptions for the economic model.

\begin{tabular}{|c|c|c|c|c|}
\hline Parameter & Description & Unit & Value & Source \\
\hline $\mathrm{CC}_{\mathrm{PV}}$ & Photovoltaic panel investment costs & $€ \cdot W p^{-1}$ & 1.1 & [54] \\
\hline $\mathrm{CC}_{\text {Bat }}$ & Battery investment costs & $€ \cdot W^{-1}$ & equation (22) & {$[56]-[60]$} \\
\hline $\mathrm{CC}_{\operatorname{lnv}}$ & Inverter investment costs & $€ \cdot W^{-1}$ & 0.225 & [54] \\
\hline $\mathrm{CC}_{\mathrm{MPPT}}$ & MPPT investment costs & $€ \cdot W p^{-1}$ & $0.06 \cdot \mathrm{CC}_{\mathrm{PV}}$ & [67] \\
\hline $\mathrm{CC}_{\mathrm{BMS}}$ & BMS investment costs & $€ \cdot W^{-1}$ & $0.0275 \cdot \mathrm{CC}_{\mathrm{Bat}}$ & [68] \\
\hline $\mathrm{CC}_{\text {System }}$ & System installation costs & $€ \cdot W p^{-1}$ & $0.1 \cdot \mathrm{CC}_{\mathrm{PV}}$ & [48] \\
\hline $\mathrm{CC}_{\mathrm{BoS}, \text { total }}$ & Balance-of-System costs & $€ \cdot W p^{-1} \cdot a^{-1}$ & $0.6 \cdot \mathrm{CC}_{\mathrm{PV}}$ & [67] \\
\hline omc $_{\text {System }}$ & System operation and maintenance costs & $€ \cdot W p^{-1} \cdot a^{-1}$ & $0.02 \cdot \mathrm{CC}_{\mathrm{PV}}$ & [48] \\
\hline İffective $_{\text {en }}$ & Annual percentage rate & - & 0.05 & - \\
\hline$r_{\text {nominal,omc }}$ & Cost increase rate & - & 0.005 & - \\
\hline
\end{tabular}

\footnotetext{
${ }^{2}$ Based on the internal data of the betteries AMPS GmbH of an active balancing BMS system.
} 
Table A. 6 NSGA-II set-up values, according to [64].

\begin{tabular}{ll}
\hline Parameter & Value \\
\hline Population size & 100 \\
Number of generations & 1300 \\
Mutation probability & 1.0 \\
Mutation distribution & 20.0 \\
Crossover probability & 1.0 \\
Crossover distribution & 15.0 \\
\hline
\end{tabular}

\section{REFERENCES}

[1] IEA, IRENA, UNSD, World Bank, and WHO, 'Tracking SDG 7: The Energy Progress Report', Washington DC, 2019.

[2] World Bank, State of electricity access report 2017. 2017.

[3] REN21 Members, 'Renewables 2019 global status report', 2019.

[4] International Electrotechnical Commission, 'Technical IEC Specification Ts 62325-502', Recomm. small Renew. energy hybrid Syst. Rural Electrif. Part 9-2 Micro-grids - Tech. IEC Specif. Ts 62325-502, 2006.

[5] Ruud Kempener, Olivier Lavagne d'Ortigue, Deger Saygin, Jeffrey Skeer, Salvatore Vinci, and Dolf Gielen, 'Off-grid Renewable Energy Systems: Status and Methodological Issues', 2015.

[6] W. Cai et al., 'Optimal sizing and location based on economic parameters for an off-grid application of a hybrid system with photovoltaic, battery and diesel technology', Energy, vol. 201, p. 117480, 2020.

[7] C. D. Rodríguez-Gallegos, D. Yang, O. Gandhi, M. Bieri, T. Reindl, and S. K. Panda, 'A multi-objective and robust optimization approach for sizing and placement of PV and batteries in off-grid systems fully operated by diesel generators: An Indonesian case study', Energy, vol. 160, pp. 410-429, 2018.

[8] C. D. Rodríguez-Gallegos, O. Gandhi, M. Bieri, T. Reindl, and S. K. Panda, 'A diesel replacement strategy for off-grid systems based on progressive introduction of PV and batteries: An Indonesian case study', Appl. Energy, vol. 229, no. August, pp. 1218-1232, 2018.

[9] M. Jaszczur, Q. Hassan, P. Palej, and J. Abdulateef, 'Multi-Objective optimisation of a micro-grid hybrid power system for household application', Energy, vol. 202, p. 117738, 2020.

[10] E. Zitzler and L. Thiele, 'Multiobjective optimization using evolutionary algorithms - A comparative case study', Parallel Problem Solving from Nature, pp. 292-301, Springer Berlin Heidelberg, 2006.

[11] M. Moncecchi, C. Brivio, S. Mandelli, and M. Merlo, 'Battery energy storage systems in microgrids: Modeling and design criteria', Energies, vol. 13, no. 8, pp. 1-18, 2020.

[12] C. Bordin, H. Oghenetejiri, A. Crossland, I. Lascurain, C. J. Dent, and D. Vigo, 'A linear programming approach for battery degradation analysis and optimization in offgrid power systems with solar energy integration', Renew. Energy, vol. 101, pp. 417-430, 2017.

[13] B. Zhao, X. Zhang, J. Chen, C. Wang, S. Member, and L. Guo, 'Operation Optimization of Standalone Microgrids Considering Lifetime Characteristics of Battery Energy Storage System', IEEE Trans. Sustain. Energy, vol. 4, no. 4, pp. 934-943, 2013.

[14] M. Sufyan, N. Abd Rahim, C. Tan, M. Muniar Azam, and R. Siti Rohani, 'Optimal sizing and energy scheduling of isolated microgrid considering the battery lifetime degradation', PLoS One, vol. 14, pp. 128, 2019.

[15] T. Khatib, I. A. Ibrahim, and A. Mohamed, 'A review on sizing methodologies of photovoltaic array and storage battery in a standalone photovoltaic system', Energy Convers. Manag., vol. 120, pp. 430-448, Jul. 2016.

[16] H. Ringkjøb, P. M. Haugan, I. M. Solbrekke, E. T. H. Zürich, and S. Pfenninger, 'A review of modelling tools for energy and electricity systems with large shares of variable renewables', Renew. Sustain. Energy Rev., vol. 96, no. August, pp. 440-459, 2018.

[17] T. Tjaden, B. Joseph, J. Weniger, and V. Quaschning, 'Repräsentative elektrische Lastprofile für Wohngebäude in Deutschland auf 1-sekündiger Datenbasis', HTW Berlin, 2015.

[18] A. J. Wright and Firth S.K., 'The nature of domestic electricity-loads and effects of time averaging on statistics and on-site generation calculations', Appl. Energy, vol. 84, no. 4, pp. 389-403, 2007.

[19] P. Stenzel, J. Linssen, J. Fleer, and F. Busch, 'Impact of temporal resolution of supply and demand profiles on the design of photovoltaic battery systems for increased self-consumption', 2016 IEEE Int. Energy Conf., pp. 1-6, 2016.

[20] T. Beck, H. Kondziella, and T. Bruckner, 'Assessing the influence of the temporal resolution of electrical load and PV generation profiles on self-consumption and sizing of PV-battery systems', Appl. Energy, vol. 
173, no. September 2017, pp. 331-342, 2016.

[21] A. Burgio, D. Menniti, N. Sorrentino, A. Pinnarelli, and Z. Leonowicz, 'Influence and impact of data averaging and temporal resolution on the assessment of energetic, economic and technical issues of hybrid photovoltaic-battery systems', Energies, vol. 13, no. 2, pp. 1-26, 2020.

[22] R. Tang, K. Abdulla, P. H. W. Leong, A. Vassallo, and J. Dore, 'Impacts of Temporal Resolution and System Efficiency on PV Battery System Optimisation', 2017 Asia-Pacific Sol. Res. Conf., 2017.

[23] Norm ISO 12405-1, 'Electrically propelled road vehicles - Test specification for lithium-ion traction battery systems - Part 1: High power applications', 2009.

[24] T. Khatib and W. Elmenreich, Modeling of Photovoltaic Systems Using MATLAB ${ }^{\circledR}$ - Simplified Green Codes. Hoboken, New Jersey: John Wiley \& Sons, Inc., 2016.

[25] G. Notton, V. Lazarov, and L. Stoyanov, 'Optimal sizing of a grid-connected PV system for various PV module technologies and inclinations, inverter efficiency characteristics and locations', Renew. Energy, vol. 35, no. 2, pp. 541-554, 2010.

[26] D. L. King, W. E. Boyson, and J. A. Kratochvill, 'Photovoltaic Array Performance Model', Albuquerque, New Mexico, 2004.

[27] J. Linssen, P. Stenzel, and J. Fleer, 'Techno-economic analysis of photovoltaic battery systems and the influence of different consumer load profiles', Appl. Energy, vol. 185, pp. 2019-2025, 2015.

[28] A. Jossen, 'Fundamentals of battery dynamics', J. Power Sources, vol. 154, no. 2, pp. 530-538, 2006.

[29] C. R. Birkl, M. R. Roberts, E. McTurk, P. G. Bruce, and D. A. Howey, 'Degradation diagnostics for lithium ion cells', J. Power Sources, vol. 341, pp. 373-386, 2017.

[30] J. Vetter et al., 'Ageing mechanisms in lithium-ion batteries', J. Power Sources, vol. 147, no. 1-2, pp. 269281, 2005.

[31] J. V. Barreras, E. Schaltz, S. J. Andreasen, and T. Minko, 'Datasheet-based modeling of Li-lon batteries', 2012 IEEE Veh. Power Propuls. Conf. VPPC 2012, no. May 2015, pp. 830-835, 2012.

[32] 'Shenzhen Smart Lion Power Battery Limited', Thunder Sky Winston Rare Earth Lithium Ion Battery Specification - WB-LYP4OAHA. [Online]. Available: en.winston-battery.com/index.php/products/powerbattery/item/wb-lyp40aha. [Accessed: 02.09.2020].

[33] O. Tremblay, L. Dessaint, and A. Dekkiche, 'A Generic Battery Model for the Dynamic Simulation of Hybrid Electric Vehicles', IEEE, pp. 284-289, 2007.

[34] D. Bernardi, E. Pawlikowski, and J. Newman, 'A General Energy Balance for Battery Systems', J. Electrochem. Soc., vol. 132, no. 1, p. 5, 1985.

[35] L. Gao, S. Liu, R. A. R. A. Dougal, Lijun Gao, Shengyi Liu, and R. A. R. A. Dougal, 'Dynamic lithium-ion battery model for system simulation', IEEE Trans. Components Packag. Technol., vol. 25, no. 3, pp. 495505, Sep. 2002.

[36] R. Spotnitz and J. Franklin, 'Abuse behavior of high-power, lithium-ion cells', J. Power Sources, vol. 113, no. 1, pp. 81-100, 2003.

[37] E. V Thomas, H. L. Case, D. H. Doughty, R. G. Jungst, G. Nagasubramanian, and E. P. Roth, 'Accelerated power degradation of Li-ion cells', J. Power Sources, vol. 124, pp. 254-260, 2003.

[38] S. Grolleau et al., 'Calendar aging of commercial graphite/LiFePO4 cell - Predicting capacity fade under time dependent storage conditions', J. Power Sources, vol. 255, pp. 450-458, 2014.

[39] M. Broussely et al., 'Main aging mechanisms in Li ion batteries', J. Power Sources, vol. 146, no. 1-2, pp. 90-96, 2005.

[40] J. Wang et al., 'Cycle-life model for graphite-LiFePO4 cells', J. Power Sources, vol. 196, no. 8, pp. 39423948, Apr. 2011.

[41] K. Amine, J. Liu, and I. Belharouak, 'High-temperature storage and cycling of C-LiFePO4/graphite Li-ion cells', Electrochem. commun., vol. 7, no. 7, pp. 669-673, 2005.

[42] G. A. Rampinelli, A. Krenzinger, and F. Chenlo Romero, 'Mathematical models for efficiency of inverters used in grid connected photovoltaic systems', Renew. Sustain. Energy Rev., vol. 34, pp. 578-587, 2014.

[43] D. U. Sauer and H. Schmidt, 'Praxisgerechte Modellierung und Abschätzung von WechselrichterWirkungsgraden', in 9. Internationales Sonnenforum - Tagungsband I, 1994, pp. 550-557.

[44] F. J. Ardakani, G. Riahy, and M. Abedi, 'Optimal sizing of a grid-connected hybrid system for north-west of Iran-case study', in 2010 9th International Conference on Environment and Electrical Engineering, 2010, pp. 29-32.

[45] K. Branker, M. J. M. Pathak, and J. M. Pearce, 'A review of solar photovoltaic levelized cost of electricity', Renew. Sustain. Energy Rev., vol. 15, no. 9, pp. 4470-4482, 2011.

[46] S. Mandelli, M. Merlo, E. Colombo, M. Moncecchi, and F. Riva, 'Novel procedure to formulate load profiles for off-grid rural areas - the Load Pro Gen software', in Energy for Sustainable Development, 2016, vol. 31, pp. 1-8. 
[47] M. Ikhsan, A. Purwadi, N. Hariyanto, N. Heryana, and Y. Haroen, 'Study of Renewable Energy Sources Capacity and Loading Using Data Logger for Sizing of Solar-wind Hybrid Power System', Procedia Technol., vol. 11, pp. 1048-1053, 2013.

[48] A. Ghafoor and A. Munir, 'Design and economics analysis of an off-grid PV system for household electrification', Renew. Sustain. Energy Rev., vol. 42, pp. 496-502, 2015.

[49] F. Sprei, 'Characterization of power system loads in rural Uganda', Lund University, Sweden, 2002.

[50] M. Bhatia and N. Angelou, 'Beyond Connections - Energy Access Redefined', Washington DC, 2015.

[51] P. Ineichen, Long term HelioClim-3 global, beam and diffuse irradiance validation. University of Geneva, 2016.

[52] 'HelioClim-3 version 5 time series data'. [Online]. Available: http://www.soda-pro.com/webservices/radiation/helioclim-3-archives-for-free. [Accessed: 02.09.2020].

[53] Global Modeling and Assimilation Office (GMAO), 'MERRA-2 tavg1_2d_slv_Nx: 2d,1-Hourly,TimeAveraged,Single-Level,Assimilation,Single-Level Diagnostics V5.12.4', 2015. .

[54] International Energy Agency, 'Trends in photovoltaic applications', 2019.

[55] IEA, Trends 2017 in Photovoltaic Applications - Survey Report of Selected IEA Countries between 1992 and 2014, 20th ed. IEA PVPS - International Energy Agency Photovoltaic Power Systems Program, 2017.

[56] P.A. Nelson, K.G. Gallagher, I. Bloom, and D.W. Dees, 'Modeling the Performance and Cost of Lithium-lon Batteries for Electric-Drive Vehicles', Chem. Sci. Eng. Div. - About Argonne Natl. Lab., 2011.

[57] Zweiter Bericht der Nationalen Plattform Elektromobilität. Berlin: Gemeinsame Geschäftsstelle Elektromobilität der Bundesregierung (GGEMO), 2011.

[58] P. Plötz, T. Gnann, A. Kühn, and M. Wietschel, 'Markthochlaufszenarien für Elektrofahrzeuge', 2013.

[59] J. Richter and Dietmar Lindenberger, Potenziale der Elektromobilität bis 2050 - Eine szenarienbasierte Analyse der Wirtschaftlichkeit, Umweltauswirkungen und Systemintegration, Endbericht. Köln: Energiewirtschaftliches Institut an der Universität zu Köln (EWI), 2010.

[60] Celine Cluzel and Craig Douglas, Cost and performance of EV batteries, Final repo. Cambridge: Element Energy Limited, 2012.

[61] A. Bejan, G. Tsatsaronis, and M. J. Moran, Thermal design and optimization. Wiley, 1996.

[62] H. Louie and P. Dauenhauer, 'Effects of load estimation error on small-scale off-grid photovoltaic system design, cost and reliability', Energy Sustain. Dev., vol. 34, pp. 30-43, 2016.

[63] T. Khatib and W. Elmenreich, 'Optimum Availability of Standalone Photovoltaic Power', Int. J. Photoenergy, vol. Article ID, p. 5 pages, 2014.

[64] K. Deb, A. Member, A. Pratap, S. Agarwal, and T. Meyarivan, 'A fast and elitist multi-objective genetic algorithm: NSGAII', IEEE Trans. Evol. Comput., vol. 6, no. 2, pp. 182-197, 2002.

[65] World Bank Group and ESMAP, 'Global Solar Atlas'. [Online]. Available: https://globalsolaratlas.info/map. [Accessed: 02.09.2020].

[66] ACOPOWER, 'HY-MPPT Series MPPT Solar Charge Controller - User Manual', 2018. [Online]. Available: https://images-na.ssl-images-amazon.com/images/I/B1F0uiO8QaS.pdf. [Accessed: 02.09.2020].

[67] S. Doig and S. Newman, 'Achieving Low-Cost Solar PV':, no. September, 2010.

[68] M. Lowe, S. Tokuoka, T. Tali, and G. Gereffi, 'Lithium-ion Batteries for Hybrid and All-Electric Vehicles: the U.S. Value Chain', Cent. Glob. Gov. Compet., vol. 1, no. October, pp. 1-77, 2010. 